\title{
Ophthalmic results in patients with macroprolactinomas treated with a new prolactin inhibitor CV 205-502
}

Hôpital Neurologique et Neurochirurgical Pierre Wertheimer, Lyon, France

Consultation d'Ophtalmologie $M$ Grochowicki

A Vighetto

$S$ Berquet

Centre de Médecine Nucléaire

Y Khalfallah

G Sassolas

Correspondence to: Dr M Grochowicki, Consultation

d'Ophtalmologie, Hôpital Neurologique et

Neurochirurgical Pierre Wertheimer, 59 Boulevard Pinel, 69003 Lyon, France.

Accepted for publication 29 June 1993

Michèle Grochowicki, Yad Khalfallah, Alain Vighetto, Serge Berquet, Geneviève Sassolas

\begin{abstract}
Macroprolactinomas are pituitary tumours which have been effectively treated medically since the introduction of bromocriptine. The visual function of 13 patients treated with a new prolactin (PRL) inhibitor CV 205-502 (Sandoz Basle), a potent and selective dopamine D2 receptor agonist, was evaluated. This is the first detailed ophthalmic report of the use of this drug in macroprolactinomas. Patients were enrolled from June 1988 to July 1990 (mean follow up 30 months). Visual function including visual acuity, ocular pressure, and visual fields was regularly controlled. Visual fields (VF) were tested with Goldmann and automatic static perimetry (Vision Monitor). Treatment was globally effective. No modifications of the visual function were observed in nine patients (six normal, three previous VF losses after surgery). In four other patients, visual function dramatically improved (regression of a III paresis, one case; disappearance of a chiasmatic syndrome, three cases). A pituitary necrosis was observed in one case and successfully cured. CV 205-502 seems to be an effective and well tolerated treatment of macroprolactinomas.
\end{abstract}

(Brf Ophthalmol 1993; 77: 785-788)

For 10 years, dopamine agonists have been used in the treatment of macroprolactinomas, either as a preparation for surgical removal, or as a unique treatment. ${ }^{1}$ CV 205-502 (octahydrobenzo [g] quinoline) is a new non-ergot long acting prolactin inhibitor, a pure D2 agonist. For 2 years several clinical teams have reported the first results in the treatment of macroprolactinomas..$^{2-8}$ It was shown that CV 205-502 was effective in the treatment of macroprolactinomas in cases in which bromocriptine was poorly tolerated or ineffective. ${ }^{8} \mathrm{CV} 205-502$ is well tolerated and its long action makes one dose a day possible. CV 205-502 can induce normalisation of prolactin (PRL) secretion and a noticeable reduction in tumour size. In the control of tumour volume, ophthalmic controls are essential. In this study we present the ophthalmic results in 13 patients treated with this new drug, with a mean follow up of 30 months. The early results in eight patients after 9 months of treatment have been published previously. ${ }^{3}$ To our knowledge, this is the first detailed ophthalmic report of the use of this drug in macroprolactinomas.

\section{Material and methods}

This open study was designed by Sandoz Ltd
(Basle, Switzerland) and approved by our institutional ethics committee. Thirteen patients with
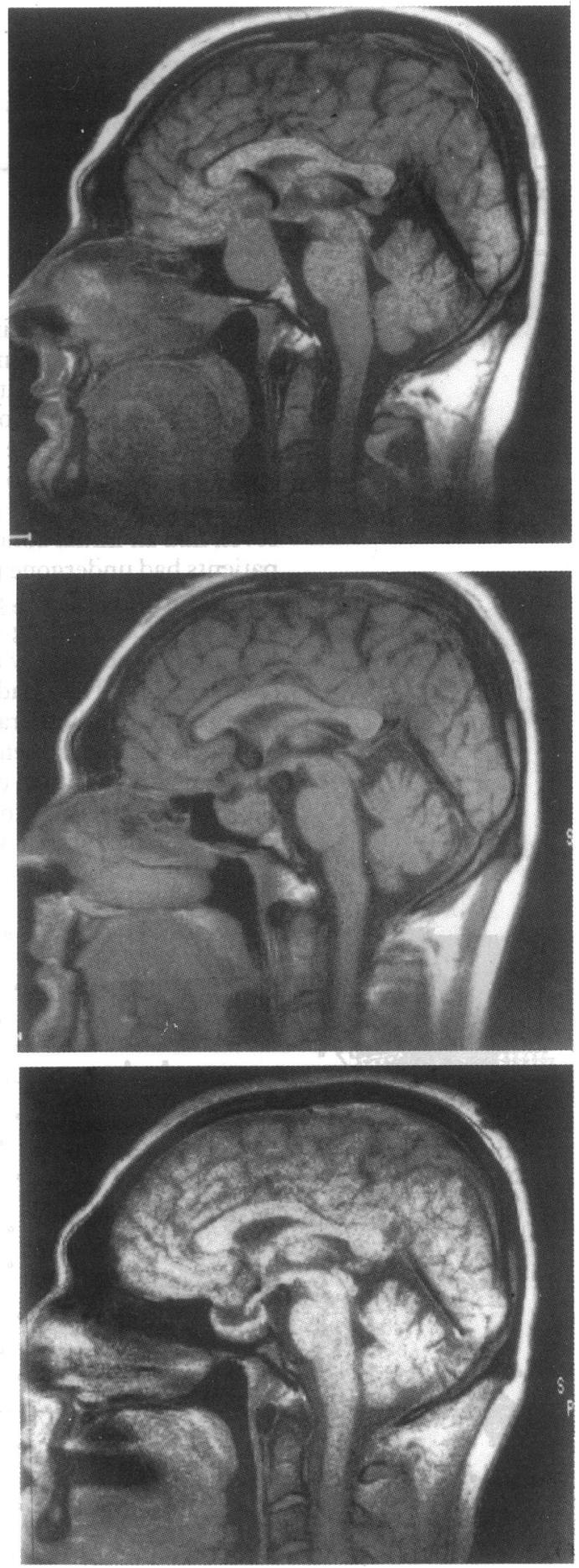

Figure 1 An example of a reduction of more than $50 \%$ in the size of the macroadenoma is given in patient 4 . On sagittal section MRI (upper) before CV 205-502 treatment; (middle) after 5 months; (lower) after 16 months of treatment. 
Table 1 Visual signs of 13 patients with macroadenomas treated with CV 205-502

\begin{tabular}{|c|c|c|c|c|}
\hline $\begin{array}{l}\text { Patient } N o \text { / } \\
\text { sex/age } \\
\text { (years) }\end{array}$ & $\begin{array}{l}\text { Clinical } \\
\text { history }\end{array}$ & $\begin{array}{l}\text { Visual signs } \\
\text { before treatment }\end{array}$ & $\begin{array}{l}\text { Evolution with } \\
\text { CV 205-502 }\end{array}$ & $\begin{array}{l}\text { Follow up } \\
\text { (months) }\end{array}$ \\
\hline $1 \mathrm{~F} 25$ & $\mathrm{~S} 2 \mathrm{~m}$ before & $\begin{array}{l}\text { Bitemporal hemianopia } \\
\text { RE: } 6 / 6, \text { LE: } 6 / 9\end{array}$ & Unchanged & 41 \\
\hline $\begin{array}{l}2 M 43 \\
3 \text { M } 29\end{array}$ & $\begin{array}{l}\text { S } 4 \mathrm{~m} \text { before } \\
\text { de novo }\end{array}$ & $\begin{array}{l}\text { Normal } \\
\text { Bitemporal quadrantic defect } \\
\text { RE: } 6 / 6, \mathrm{LE}: 6 / 9\end{array}$ & $\begin{array}{l}\text { Unchanged } \\
\text { Normalised (1 m) }\end{array}$ & $\begin{array}{l}34 \\
41\end{array}$ \\
\hline $4 M 30$ & de novo & $\begin{array}{l}\text { Bitemporal hemianopia } \\
\text { RE: } 6 / 9 \text {, LE: } 6 / 6\end{array}$ & Improved (4 m) & 40 \\
\hline $\begin{array}{l}5 \text { M } 38 \\
6 \text { M } 46 \\
7 \text { M } 21 \\
8 \text { F } 33\end{array}$ & $\begin{array}{l}\text { S } 9 \mathrm{~m} \text { before } \\
\text { de novo } \\
\text { S } 3 \mathrm{~m} \text { before } \\
\text { S } 9 \mathrm{~m} \text { before }\end{array}$ & $\begin{array}{l}\text { Normal } \\
\text { Normal } \\
\text { Normal } \\
\text { Slight quadrantic defect } \\
\text { right VF, RE:LE: } 6 / 6\end{array}$ & $\begin{array}{l}\text { Unchanged } \\
\text { Unchanged } \\
\text { Unchanged } \\
\text { Unchanged }\end{array}$ & $\begin{array}{l}43 \\
43 \\
39 \\
35\end{array}$ \\
\hline $\begin{array}{l}9 \mathrm{~F} 20 \\
10 \mathrm{M} 63\end{array}$ & $\begin{array}{l}\text { S } 2 \mathrm{~m} \text { before } \\
\text { de novo }\end{array}$ & $\begin{array}{l}\text { Normal } \\
\text { Unitemporal scotoma } \\
\text { RE:LE: } 6 / 6\end{array}$ & $\begin{array}{l}\text { Unchanged } \\
\text { Improved (1 m) } \\
\text { pituitary } \\
\text { necrosis } \\
(16 \mathrm{~m}), \mathrm{RE}: 6 / 9 \text {, } \\
\text { LE: } 6 / 12\end{array}$ & $\begin{array}{l}31 \\
24\end{array}$ \\
\hline $11 \mathrm{~F} 35$ & S 8 y before & $\begin{array}{l}\text { Left III paresis } \\
\text { RE: } 6 / 6, \text { LE: } 6 / 9\end{array}$ & $\begin{array}{r}\text { Normalised } \\
(6 \text { weeks })\end{array}$ & 16 \\
\hline 12 M 38 & $S 5$ y before & $\begin{array}{l}\text { Left, HLH and strabic amblyopia; } \\
\text { R, III palsy RE: } 6 / 6, \text { LE: } 6 / 60\end{array}$ & Unchanged & 29 \\
\hline $13 \mathrm{M} 42$ & S $7 \mathrm{~m}$ before & Normal & Unchanged & 29 \\
\hline
\end{tabular}

$S=$ surgery, de novo $=$ de novo cases.

$\mathrm{m}=$ month, $\mathrm{y}=$ years.

$R E=$ right eye; $\mathrm{LE}=$ left eye

$\mathrm{VF}=$ visual field, $\mathrm{HLH}=$ homonymous lateral hemianopia

macroprolactinomas, nine men and four women agreed to participate in the present study and gave their informed written consent.

They were referred to our institution during a 2 year period from June 1988 to July 1990 . Their ages ranged from 20 to 63 years (mean 35). Six patients had an initial normal visual function, seven had an initial abnormal one. Nine of these patients had undergone pituitary surgery (Nos 1 , $2,5,7,8,9,11,12,13)$, seven as recently as 2 to 7 months before starting the trial; the two others had undergone surgery 8 and 5 years previously (Nos 11, 12). They had not been submitted to postoperative radiotherapy. Six of them had had bromocriptine treatment. A 2 month wash out period before initiation of CV 205-502 treatment allowed plasma PRL to return to pretreatment levels and the tumour volume increased again.

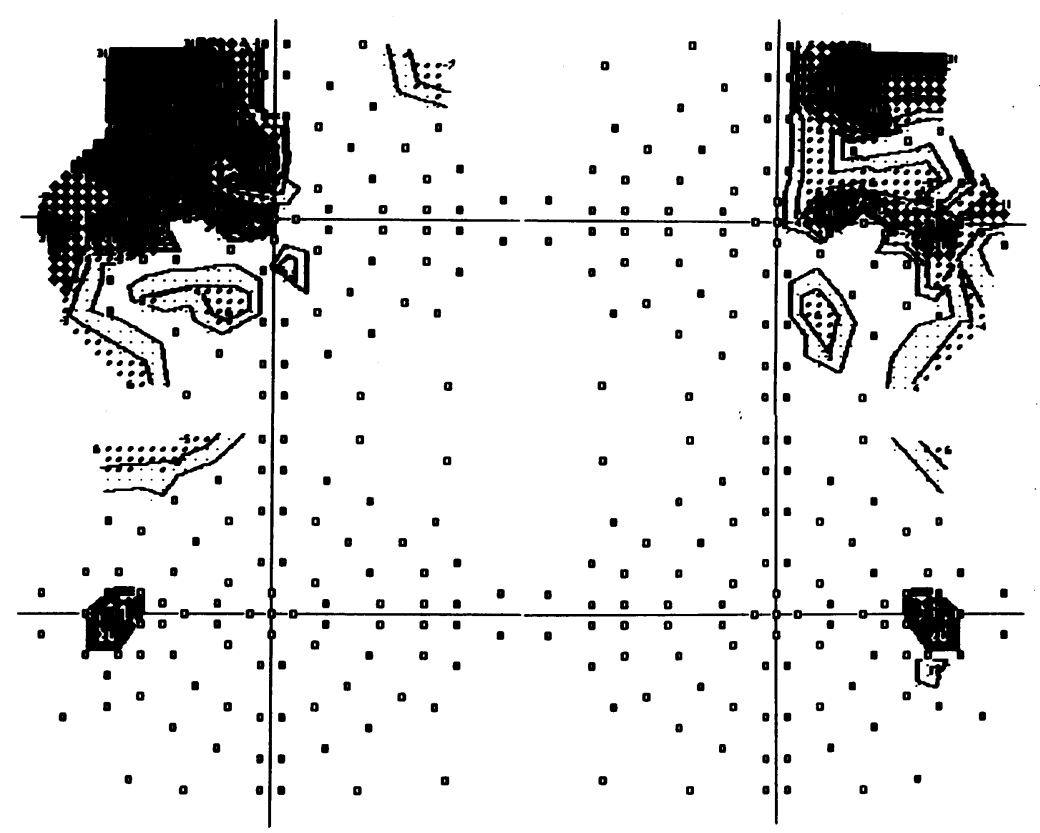

Figure 2 Evolution of visual field in patient 3 with a de novo macroadenoma. The bitemporal hemianopia is observed before treatment with CV 205-502 (upper); the visual field is normal after 1 month of treatment (lower).
Tumour remnants were visible on computed tomographic scan (CT) or magnetic resonance imaging (MRI).

The four patients who had not been operated on (de novo cases) had pituitary tumours larger than $20 \mathrm{~mm}$ in diameter, with suprasellar extension in four cases (Nos 3, 4, 6, 10) and laterosellar extension in three (Nos 3, 6, 10). Two of these patients (Nos 4, 10) had been treated with bromocriptine for 2 and 5 months respectively.

During the 2 months before treatment was started, plasma PRL levels were determined twice, and tumor imaging was performed by high resolution CT scan or MRI. ${ }^{3}$ CV 205-502 doses administered at bedtime with a snack, were increased every 3 days from $0.025 \mathrm{mg}$ to 0.075 mg. The dose of CV 205-502 was modified according to PRL levels and increased by steps of $0.075 \mathrm{mg}$ until normalisation. The follow up of the evolution ranged from 16 to 43 months with a mean of 33 months. Hormonal and radiological controls were regularly undertaken. ${ }^{3}$

Ophthalmic controls were undertaken systematically before treatment and after 2 weeks, after 3 months, and 6 months during the first year of treatment, thereafter every year. Each ophthalmic control included an ophthalmic examination (control of visual acuity, ocular pressure, and fundus). A comparison of the ocular pressure before treatment and at the last control was made. As the physician and the slit-lamp could be different, the ocular pressure was considered unchanged if the difference was $\leqslant 2 \mathrm{~mm} \mathrm{Hg}$. The colour of the optic disc was evaluated by funduscopy as normal or pale. At the same time, visual fields (VF) were carried out associating a kinetic perimetry of Goldmann with 3 isoptres (V4, II2, I2) and a static automatic perimetry of the $30^{\circ}$ on the Vision Monitor using a previously described technique.'

\section{VISUAL FIELD: PARAMETERS OF EVALUATION}

With both techniques the VF was first evaluated qualitatively. Automated visual fields were compared with a map of normal subjects, matched for age and included in the perimeter. As a secondary control, the comparison of one of the parameters, the 'mean total deficit,' before treatment and at the last test could be established using the $t$ test.

VF was considered to be normal when compared with the map in the device. Abnormal VF were identified as bitemporal hemianopia when the deficit was complete; quadrantic defect (uni or bitemporal) when the defect was limited to a temporal quadrant, usually superior, homonymous lateral hemianopia; or isolated scotoma. In patient No 4, in addition to the chiasmatic syndrome, a temporal absolute irreversible scotoma correlated to a choroidal scar was identified; the visual field of this case has been previously documented. ${ }^{3}$

\section{VISUAL FIELD: PARAMETERS OF CHANGE}

The VF was considered as unchanged, normal, or abnormal if no significant difference between the VF before treatment and at the last control was observed; normalised if it was normal when 


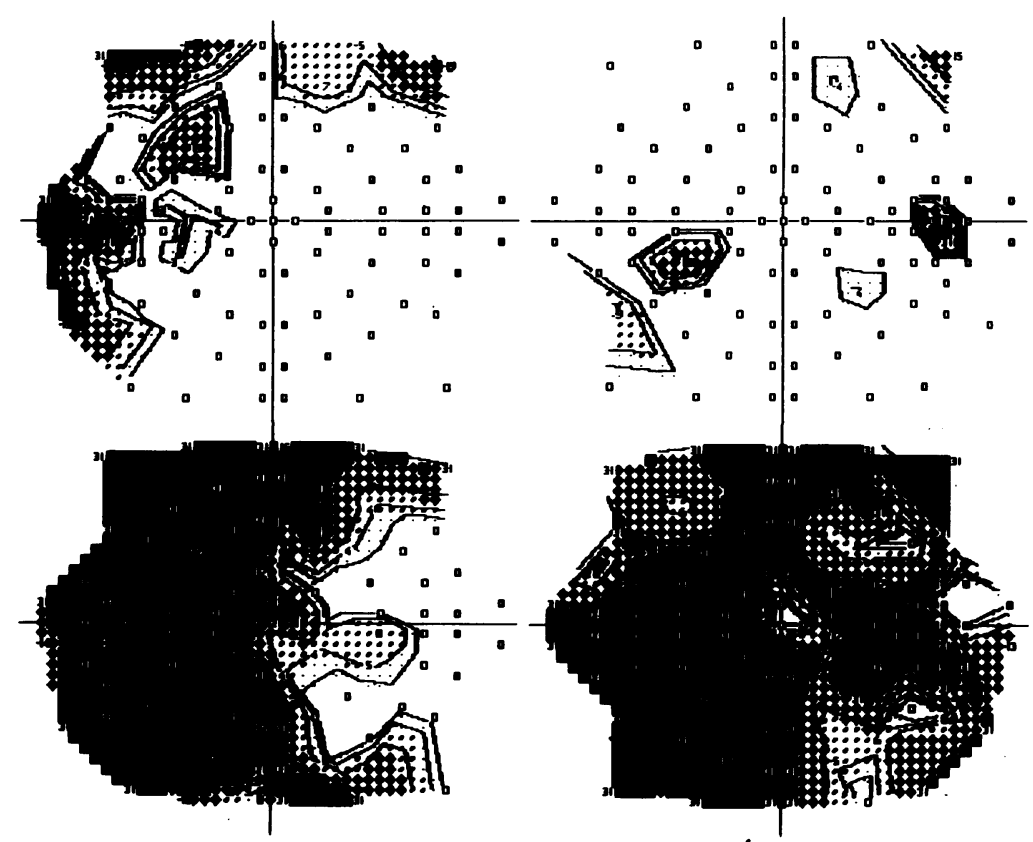

Figure 3 Visual field (VF) of patient 10; (upper) the deficit is limited to an irregular left temporal scotoma after 13 months of treatment with CV 205502. (Lower) corresponds to the beginning of pituitary necrosis after 16 months of medical treatment with visual failure $(L E=6 / 18$; $R E=6 / 9$ ), huge central scotoma on the $R E$,

temporal hemianopia on the LE. compared with the map in the device; improved when a regression of more than $50 \%$ of the VF defect was observed qualitatively and quantitatively.

\section{Results}

The overall tolerance was good. ${ }^{3}$ A normalisation of prolactinaemia was observed in 12 out of 13

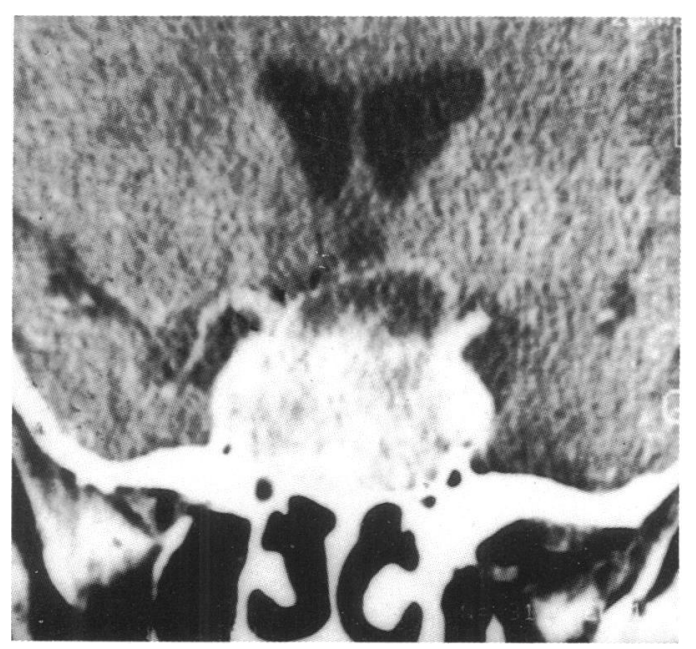

cases and a considerable reduction of the prolactinaemia in one. The reduction in the tumour volume was superior or equal to $50 \%$ in eight cases out of 13 (illustrated in Fig 1). The visual tolerance was good. In all the cases the ocular pressure was $\leqslant 20 \mathrm{~mm} \mathrm{Hg}$. During the first year of treatment, modifications of the ocular pressure were observed: five with a mean reduction of 4 $\mathrm{mm} \mathrm{Hg}$, three with a mean increase of $3 \mathrm{~mm} \mathrm{Hg}$. These modifications were transient. There was no difference between the ocular pressure measured before the treatment and at the last control. The aspect of the optic disc remained unchanged during the treatment; 10 were normal, three were pale. The visual results including visual acuity and visual field before inclusion were normal in six cases and abnormal in seven cases.

BASELINE NORMAL VISUAL FUNCTION (TABLE 1) Six patients had an initial normal visual function: visual acuity and visual fields were normal in one de novo case (No 6) and five who had undergone surgery (Nos $2,5,7,9,13)$. No visual complication was observed under treatment with CV 205502 with a range of observation from 30 to 43 months. A certain degree of variability in the visual fields was observed; variable and regressive relative scotomas were present without modifications of the prolactin levels, but there was no significant difference between the mean total deficit before and after treatment ( $t$ test).

BASELINE ABNORMAL VISUAL FUNCTION (TABLE 1) Four of these patients had undergone previous pituitary surgery (Nos 1, 8, 11, 12), three were de novo cases (Nos $3,4,10$ ).

In three patients (Nos $1,8,12$ ) with alterations of visual field, sequelae of previous pituitary surgery, no amelioration was observed. Some variations of the VF were observed in case 8 . In case 12, who had a left strabismic amblyopia, the left homonymous lateral hemianopia was associated with a III right palsy, sequelae of pituitary surgery performed 5 years before. In case 11 , an isolated left III paresis was observed 8 years after the patient had undergone pituitary surgery. The regression of the ptosis and the diplopia was observed after only 6 weeks of medical treatment. An excellent and quick regression of visual field abnormalities was observed in the three de novo cases (Nos 3, 4, 10). A complete normalisation was observed in 1 month in case 3 (Fig 2). In the two other cases VF improved in 4 months and 1 month respectively.

We shall examine case No 10 in more detail. After 16 months of closely monitored treatment, the reduction of the volume of the tumour on CT scan was incomplete in spite of a good control of prolactinaemia and an improved VF. The patient suddenly complained of headache and his vision decreased bilaterally from normal to RE: 6/9, LE: 6/18 to (lower part of Fig 3) and to 'no light perception' in either eye associated with a right ptosis within 2 days. On the CT scan a heterogeneous aspect of the macroadenoma associated with an increase of size was compatible with the diagnosis of pituitary necrosis (Fig 4). 
Surgical treatment with a trans-sphenoidal approach was quickly carried out. The visual acuity of the patient rapidly improved and reach $6 / 9$ and 6/12 1 month after surgery. In spite of a good anatomical result the PRL level rose and the patient was again treated with dopamine agonist CV 205-502. The visual field undertaken 8 months later remained improved.

\section{Discussion}

In our study, CV 205-502 was effective in the treatment of macroprolactinomas. In our 13 cases, six patients had a normal baseline visual function and maintained it during a mean follow up of 30 months. Some variations of their visual fields were observed at different checks without statistically significant differences. However, no clear explanation for these modifications could be given, PRL levels remaining normal at the same time. A transient modification of the size of the tumour could not be excluded since repeated radiological investigations were impossible. The visual abnormalities we observed did not differ from those previously published. The evolution of visual signs under treatment is summarised in Table 2 using the authors' own, sometimes imprecise, terminology. There is an important difference between an intractable visual field defect after surgery and a visual field hemianopia in de novo cases. In our three patients who had been submitted to previous surgery visual field losses remained unchanged as in a case of Vance. ${ }^{5}$

In the three de novo cases, the positive and rapid effect in reduction of the visual field loss was obtained, as described previously, between 4 and 8 weeks. ${ }^{25}$ In patients with laterosellar extension of macroprolactinoma as in case 11 , the use of a dopamine agonist is a good alternative to high risk surgery. Resolution of diplopia is effective (case 6 of Van Verlaat ${ }^{6}$ and in the second case of Vance $^{5}$ ). Despite the normalisation of plasma PRL levels, tumoral tissue may still be present in large amounts. There is a discrepancy between the antisecretory and the antitumoral responses, ${ }^{3}$ which has been previously reported with bromocriptine. ${ }^{10}$ In our case 10 , no complete shrinkage of the tumour was observed in spite of a normalisation of visual field and endocrine parameters. There were no signs predicting pituitary necrosis. CV 205-502 is an effective and well tolerated treatment of macroprolactinomas with few side effects. However, a visual risk of pituitary necrosis remains. ${ }^{11}$ A regular control of ophthalmic function is mandatory as with the other dopamine agonists.

1 Molitch ME, Elton RL, Blackwel RO, Caldwell B, Chang RJ, Jaffe $\mathbf{R}$, et al. Bromocriptine as primary therapy for prolactin-secreting macroadenomas: results of a prospective multicenter study. F Clin Endocrinol Metab 1985; 60:

2 Barnett PS, Dawson JM, Butler J, Coskeran PB, Maccabe JJ, McGregor AM. CV 205-502, a new non-ergot dopamine agonist, reduces prolactinoma size in man. Clin Endocrinol 1990; 33: 307-16.

3 Khalfallah Y, Claustrat B, Grochowicki M, Flocard F, Horlait $S$, Serusclat $P$, et al. Effects of a new prolactin inhibitor, $C V$ 205-502, in the treatment of human macroprolactinomas. fClin Endocrinol Metab 1990; 71: 354-9.

4 Serri O, Beauregard H, Lesage J, Pedneault I, Comtois R, Jilwan $\mathrm{N}$, et al. Long term treatment with CV 205-502 in patients with prolactin-secreting pituitary macroadenomas. patients with prolactin-secreting pituitary

5 Vance ML, Lipper M, Klibanski A, Biller BMK, Samaan NA, Molitch ME. Treatment of prolactin-secreting pituitary macroadenomas with the long-acting non-ergot dopamine agonist CV 205-502. Ann Intern Med 1990; 112: 668-73.

6 Van't Verlaat JW, Croughs RJM, Brownell J. Treatment of macroprolactinomas with a new non-ergot, long-acting dopaminergic drug CV 205-502. Clin Endocrinol 1990; 33: 619-24.

7 Crottaz B, Uske A, Reymond MJ, Rey F, Siegel RA, Brownel $\mathrm{J}$, et al. CV 205-502 treatment of macroprolactinomas. fEndocrinol Invest 1991; 14: 757-62.

8 Duranteau L, Chanson P, Lavoinne A, Lubetzki J, Kuhn JMS. Effect of the new dopaminergic agonist CV 205-502 on plasma prolactin levels and tumour size in bromocriptineresistant prolactinomas. Clin Endocrinol 1991; 34: 25-9.

Grochowicki M, Vighetto A, Berquet S, Khalfallah Y, Sassolas G. Pituitary adenomas: automated static perimetry and Goldmann perimetry. A comparative study of 345 visual
field charts. Br $\mathcal{O}$ Ophthalmol $1991 ; 75: 219-21$.

10 Bevan JS, Webster J, Burke CW, Scanlon MF. Dopamine agonists and pituitary tumour shrinkage. Endocrine Rev 1992; 13: $220-40$.

11 Lawton NF. Prolactinomas: medical or surgical treatment? $Q \mathcal{F}$ Med New Series 1987; 64: 557-64. 